(2) Open Access Full Text Article

\title{
Temporary diplopia upon hyoscine-N-butyl bromide administration: case report
}

This article was published in the following Dove Press journal:

Clinical Ophthalmology

22 May 2013

Number of times this article has been viewed

\section{R Migliorini \\ R Malagola \\ M Mafrici \\ R Spena \\ L Arrico}

Department of Sense Organs, University of Rome "La Sapienza", Rome, Italy
Correspondence: L Arrico

Department of Sense Organs, University of Rome "La Sapienza",

Via del Policlinico 155, 00161 Rome, Italy

Tel +39335 6900888

Fax +39065576577

Email loredana.arrico@uniromal.it
Abstract: Hyoscine-N-butyl bromide is a widely used antispasmodic belonging to the belladonna alkaloid class of semisynthetic quaternary ammonium compounds. These compounds exert a spasmolytic action on the smooth muscles of the bile-gastrointestinal tract, genitourinary tract, salivary glands (xerostomia), and also on the visual apparatus - in particular, the irido-ciliary complex. As a consequence, they provoke collateral effects such as mydriasis and accommodation disturbances. We report the case of a 23-year-old woman who complained of not only "dry mouth" but also "cloudy vision" and a "diplopia", both of temporary type, 2 hours after oral administration of hyoscine-N-butyl bromide.

Keywords: hyoscine-N-butyl bromide, accommodation disorders, temporary diplopia, fusion alteration, vertical strabismus

\section{Introduction}

Hyoscine-N-butyl bromide (HBB) is a widely used antispasmodic and anticholinergic drug belonging to the belladonna alkaloid class of semisynthetic quaternary ammonium compounds. These compounds exert a spasmolytic action on the smooth muscles of the bile-gastrointestinal tract, ${ }^{1}$ the genitourinary tract, the salivary glands (xerostomia), ${ }^{2}$ and also on the visual apparatus at an ocular level - in particular, the irido-ciliary complex. As a consequence, they provoke collateral effects such as mydriasis and accommodation disturbances..$^{3,4}$

We report the case of a 23-year-old woman who complained of accommodation disturbances and a "diplopia" upon oral administration of HBB.

\section{Case report}

The patient (23 years old) attended the Department of Sense Organs, University of Rome "La Sapienza", Rome, Italy, 2 hours after administration of one pill of Buscopan ${ }^{\circledR}$ (Boehringer Ingelheim, Ingelheim, Germany) complaining about "double vision" in the primary position and "cloudy vision" in the left eye (LE) more than in the right eye (RE), in addition to "dry mouth".

The patient was quickly sent to our ocular motility center, where she underwent an ophthalmologic examination 2 hours after drug administration. She was also reexamined after 2 days, 1 week, and 1 month.

The examination included the following tests:

- Best refraction test for far and near vision

- Test of the anterior segment through slit-lamp biomicroscope 
- Fondus oculi test through indirect Schepens ophthalmoscopy

- Goldmann applanation tonometry.

During each examination, ocular motility was analyzed through a corneal reflex test, cover test, diplopia trial, Wirt test, Worth test, and Hess screen.

Laboratory examinations, radiological analyses, and neurologic and internistic visits were carried out in order to exclude the most frequent causes of diplopia in adulthood, such as virus infection, hypertension, diabetes, toxic factors, and neurological or demyelinating diseases..$^{5-7}$

The previous ophthalmologic visits in other medical centers had shown a natural visual acuity of $10 / 10$ in both eyes and an ocular motility without any particular alteration.

At our first check (2 hours after drug administration), the patient presented visual acuity in the RE of $10 / 10$ and in the LE of 8/10. In the last one, visual acuity reached 10/10 after the addition of $+1 \mathrm{D}$ spherical lens. In both eyes, the acuity at near vision conformed to the I character. Examination of the anterior segment detected pupil anisocoria $(\mathrm{LE}>\mathrm{RE}){ }^{8}$ Intraocular pressure and fundus examination were normal. The ocular motility tests detected a slight vertical deviation increasing in the sight downward and decreasing in an anomalous position. The Hess screen revealed a slight deficit of the superior oblique muscle of the LE, and the Bielschowsky test was positive.

At the second check, after 2 days, natural visual acuity was $10 / 10$ in both eyes, without the need to correct the hypermetropia of the LE detected in the previous check. Visual acuity at near distance remained unchanged but without any correction in the LE. The examination of the anterior segment did not detect anisocoria. Intraocular pressure and fundus examination were normal.

With regard to ocular motility, the diplopia test with red filter on the RE revealed a higher diplopia of the sight downward and to the right with white lower light. Specifically, a hypofunction of the superior oblique muscle of the LE was evident and a hyperfunction of the inferior rectus muscle of the RE (Figure 1). Also present was a hyperfunction of the inferior oblique muscle of the LE and a hypofunction of the superior rectus muscle of the RE. The Bielschowsky sign was positive, with consequent anomalous position of the head inclined to the right. The Wirt test was normal (normal stereoscopic sense). The Worth test highlighted a diplopia at near distance, which was compensated for by the patient with a modification of the head position. This picture was further confirmed by the Hess screen test. The laboratory analyses (neurological and radiological) excluded toxic factors and

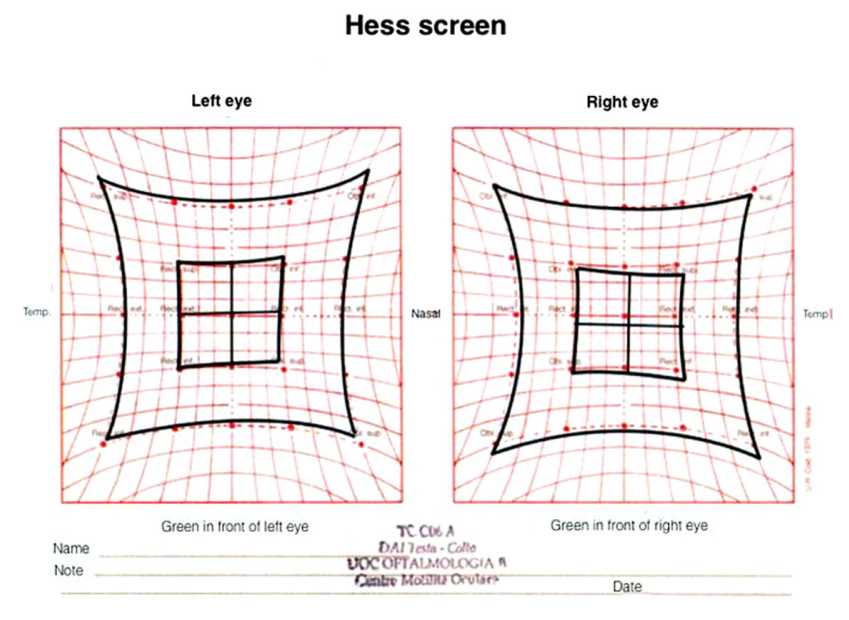

Figure I The Hess screen revealed a hypofunction of the superior oblique muscle and a hyperfunction of the inferior rectus muscle of the right eye.

systemic neurological or demyelinating pathologies of adult diplopia (either chronic or acute).

At the third check, after 1 week, visual function was full and all alterations of ocular motility (slight hypofunction of the superior oblique muscle of the LE and slight hyperfunction of the inferior rectus of the RE) were not observed (Figure 2).

At the fourth check, carried out after 1 month, the clinical picture was as in the third check.

\section{Discussion}

$\mathrm{HBB}$, an antispasmodic and anticholinergic drug belonging to the belladonna alkaloid class of semisynthetic compounds, as a quaternary ammonium derivative, does not involve the central nervous system, as it does not cross the hematoencephalic barrier. ${ }^{8,9}$ In the reported case, the anticholinergic effect acted at a peripheral level (through blocking the locoregional ganglia and antimuscarinic activity), causing, in

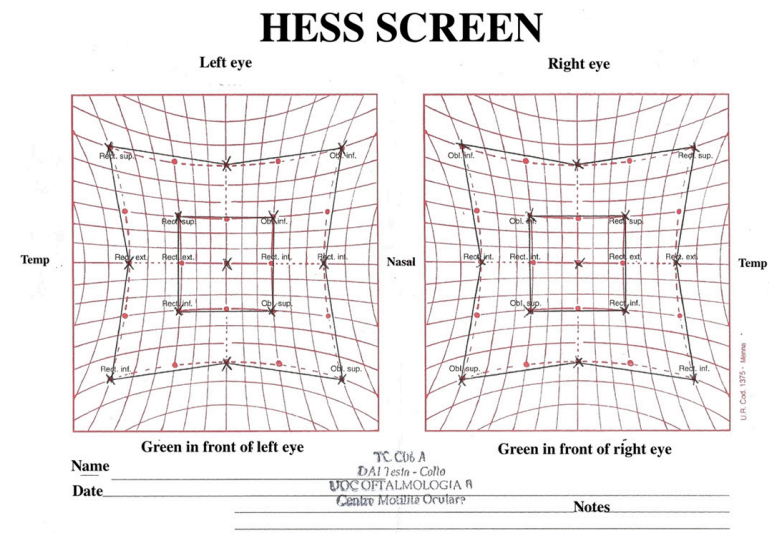

Figure 2 The Hess screen revealed a normal binocular muscular function after 7 days and I month. 
addition to oral drying, the ocular disturbances recorded at the first check: mydriasis, accommodation disorders, ${ }^{3}$ and, as a consequence, diplopia.

Because HBB, in general, does not act directly on the skeletal muscle tissue, most likely the observed temporary diplopia was not due to a direct action of the drug on the oculomotor muscles. It is possible that it could have been due to the cycloplegic effect on the accommodation of LE, which was able to alter the mechanism of sensory-motor fusion and highlight a hypofunction of the superior oblique muscle of the LE.

The latter was evident either by the positivity of Biesholwky sign or by the red filter diplopia trial. Such a hypothesis is supported by the fact that even 1 month after the disappearance of symptoms and diplopia, the persistence of the functional alteration of the oculomotor muscles was not confirmed.

It could be supposed that the LE, in normal conditions, by exerting an accommodation power of $+1 \mathrm{D}$, is able to maintain the function of the oculomotor muscles of both eyes in a balanced condition, allowing them to remain in axis in all sight positions.

\section{Conclusion}

In the reported case, it is likely that $\mathrm{HBB}$ was the causal factor of the diplopia, due to a partial block of the accommodation. As a consequence, because a latent hypermetropia was present in the LE, the fusional balance (sensory and motor) maintaining the orthophoria was probably broken.

Furthermore, the consequent diplopia of the patient was peculiar because instead of the most common horizontal deviation there was a transient, vertical deviation associated with a hypofunctionality of the superior oblique muscle of the LE and a secondary hyperfunctionality of the inferior rectus muscle of the $R E$.

\section{Disclosure}

The authors report no conflicts of interest in this work.

\section{References}

1. Sissons GR, McQueenie A, Mantle M. The ocular effects of hyoscinen-butylbromide ("Buscopan") in radiological practice. Br J Radiol. 1991;64:584-586.

2. Ventafridda V, Ripamonti C, Caraceni A, Spoldi E, Messina L, De Conno F. The management of inoperable gastrointestinal obstruction in terminal cancer patients. Dose-response relationships of intravenous hyoscine butylbromide and atropine sulphate on heart rate in healthy volunteers. Tumori. 1990;76:389-393.

3. Mehlfeld G, Bleichert A. The effect of anticholinergic drugs on the inner eye muscles. Graefe's Arch Clin Exp Ophthalmol. 1986;224:92-95.

4. Bouin M, Lupien F, Riberdy-Poitras M, Poitras P. Tolerance to gastric distension in patients with functional dyspepsia: modulation by a cholinergic and nitrergic method. Eur J Gastroenterol Hepatol. 2006;18: 63-68.

5. Dyde R, Chapman AH, Gale R, Mackintosh A, Tolan DJ. Precautions to be taken by radiologists and radiographers when prescribing hyoscineN-butylbromide. Clin Radiol. 2008;63:739-743.

6. Dyde R, Chapman AH, Gale R, Mackintosh A, Tolan DJ. Precautions to be taken by radiologists and radiographers when prescribing hyoscineN-butylbromide. Br J Clin Pharmacol. 1983;16:623-626.

7. Mehlfeld G, Bleichert A. The problem of the impairment of the action of parasympatholytic substances. Ophthalmologic criteria and methods. Arzneimittelforschung. 1986;36:271-273.

8. Sotos Rubio R, Sarrias Lorenzo E, Moreno Salcedo JM, Beato Pérez JL, Rueda Narváez MV, Fernández Gómez JM. Mydriasis due to accidental use of butylscopolamine. Enferm Clin. 2010;20:270.

9. Litta-Modignani R, Mazzolari M, Barantani E, Bertoli D, Vibelli C. Relative potency of the atropine-like effects of a new parasympatholytic drug, scopolamine (cyclopropyl methyl) bromide and those of hyoscineN-butyl bromide. Curr Med Res Opin. 1977;5:333-340.
Clinical Ophthalmology

\section{Publish your work in this journal}

Clinical Ophthalmology is an international, peer-reviewed journal covering all subspecialties within ophthalmology. Key topics include: Optometry; Visual science; Pharmacology and drug therapy in eye diseases; Basic Sciences; Primary and Secondary eye care; Patient Safety and Quality of Care Improvements. This journal is indexed on

Submit your manuscript here: http://www.dovepress.com/clinical-ophthalmology-journal

\section{Dovepress}

PubMed Central and CAS, and is the official journal of The Society of Clinical Ophthalmology (SCO). The manuscript management system is completely online and includes a very quick and fair peer-review system, which is all easy to use. Visit http://www.dovepress.com/ testimonials.php to read real quotes from published authors. 